DDH is essential in all newborns, physical examinations revealing alterations must be complemented with ultrasound imaging study to avoid the delayed diagnosis of the condition and therefore decrease incidence of the complications.

\section{Reference}

1.Mubarak, Scott, et al. "Pitfalls in the use of the Pavlik harness for treatment of congenital dysplasia, subluxation, and dislocation of the hip." J Bone Joint Surg Am 63.8 (1981): 1239-1248.

2.Stein-Zamir, Chen, et al. "Developmental dysplasia of the hip: risk markers, clinical screening and outcome." Pediatrics International 50.3 (2008): 341-345.

3.Wang, Ya-Jie, et al. "Association between open or closed reduction and avascular necrosis in developmental dysplasia of the hip: A PRISMAcompliant meta-analysis of observational studies." Medicine 95.29 (2016).9. Kalamchi A, MacEwen GD. Avascular necrosis following treatment of congenital dislocation of the hip. J Bone Joint Surg Am. 1980;62:876e888.

4.Cooperman, DANIEL R., Richard Wallensten, and S. D. Stulberg. "Post-reduction avascular necrosis in congenital dislocation of the hip." The Journal of bone and joint surgery. American volume 62.2 (1980): 247-258.

5.Rampal, V., et al. "Closed reduction with traction for developmental dysplasia of the hip in children aged between one and five years." The Journal of bone and joint surgery. British volume 90.7 (2008): 858-863.

6.Li, Lianyong, et al. "CX3CR1 polymorphisms associated with an increased risk of developmental dysplasia of the hip in human." Journal of Orthopaedic Research 35.2 (2017): 377-380.

7.Burhan, M.H. and Hattab, K.M., 2019. Effectiveness of Health Educational Program on Nurses' Knowledge Concerning of Developmental Hip Dysplasia at Al-Wasiti Teaching Hospital in Baghdad City. Indian Journal of Public Health Research \& Development, 10(10), pp.1835-1840.

8.Mansoor, A.K., Kraidi, B. and Al-Naser, L.M., 2018. Simultaneous versus two stage surgical treatment of developmental dislocation of the hip with excessive femoral anteversion in children under the age of three years. Journal of Ideas in Health, 1(2), pp.34-41.

9.Pospischill, R., Weninger, J., Ganger, R., Altenhuber, J. and Grill, F., 2012. Does open reduction of the developmental dislocated hip increase the risk of osteonecrosis?. Clinical Orthopaedics and Related Research ${ }^{\circ}, 470(1)$, pp.250-260.

10.Szabo, Robert M. "Current Concepts ReviewPrinciples of Epidemiology for the Orthopaedic Surgeon." JBJS 80.1 (1998): 111-20.

11.Barlow, T. G. "Early diagnosis and treatment of congenital dislocation of the hip." The Journal of Bone and Joint Surgery. British volume 44.2 (1962): 292-301.

12.Von Rosen, Sophus. "Diagnosis and treatment of congenital dislocation of the hip joint in the newborn." The Journal of Bone and Joint Surgery. British volume 44.2 (1962): 284-291.

\title{
WORK-RELATED STRESS EVALUATION AMONG THE NURSES AT REFERRAL HOSPITALS IN MONGOLIA. /DURING THE COVID-19 PANDEMIC PERIOD/
}

\author{
DOI: 10.31618/ESU.2413-9335.2020.1.77.965 \\ Otgonbaatar $D^{1}$, Lkhagvasuren $T^{1}$, \\ Naranbaatar $N^{2}$, Munkhkhand $J^{2}$ \\ ${ }^{1}$ Mongolian National University of Medical Science, \\ ${ }^{2}$ School of nursing, Mongolian
}

\section{ABSTRACT}

Background: Occupational or work-related stress is defined as a person's response to cope with situations that make it impossible for them to perform normally due to colleagues or co-workers' relationships and the working environment. Nursing, itself, is a stress-prone profession, we cannot eliminate the stressors, but teaching nurses effective ways to deal with stress and avoid stress will allow them to focus on their work and work energetically and satisfactorily. Thus we saw the need to figure out the workplace stress among the nurses who worked in the referral hospitals in Mongolia.

Methods: The study involved a totally 473 nurses from the tertiary referral hospitals of Mongolia. We employed Work Stress Profile (WSP) questionnaire of Rice in 57 questions in 3 domains. This questionnaire was considered to determine how nurses perceive and accept the stress. The Likert scale was used in measuring the questions. The indicators were evaluated by the cross-sectional model.

Results: The survey was conducted by selecting nurses according to the age groups similar to the age pyramid of nurses working in the hospitals. Conclusion: Nursing work-related stress levels were $F=3.071, p=0,028$; and it expressed statistical significant differences regarding the ANOVA analysis.

Keywords: stress, work, nurse

\section{Background}

In recent years, there have been a number of stressors, such as emotional instability, anxiety, and worry, due to a variety of factors, including social and economic conditions, drastic changes in science, technology, information, urbanization, and overcrowding. The stability and improvement in social wellbeing mostly depend on the personnel who work in the healthcare system. Thus, the work-related or workplace stress among the nurses who are considered as the closest people to a client is needed to be studied. 


\section{Purpose}

The purpose of our study is to find out whether the referral hospital nurses have the work stress.

\section{Materials and Methods}

The study was conducted at the Mongolian National Centers of Traumatology and Orthopedics (1), Infectious Diseases (2), Cancers (3) and Mental Health (4) in February-April, 2020, by cross-sectional model of research among the 473 nurses.

We employed a Work Stress Profile (WSP) questionnaire of Rice - in 57 questions in 3 domains; the questions aim to assess the co-workers relations (1$26)$, the working environment (27-48) and the personal attributes (49-57). This questionnaire was considered to figure out how nurses perceive and accept the stress. The Likert scale was used in measuring the questions. The indicators were evaluated by a cross-sectional model. The study result tables/graphics and statistical

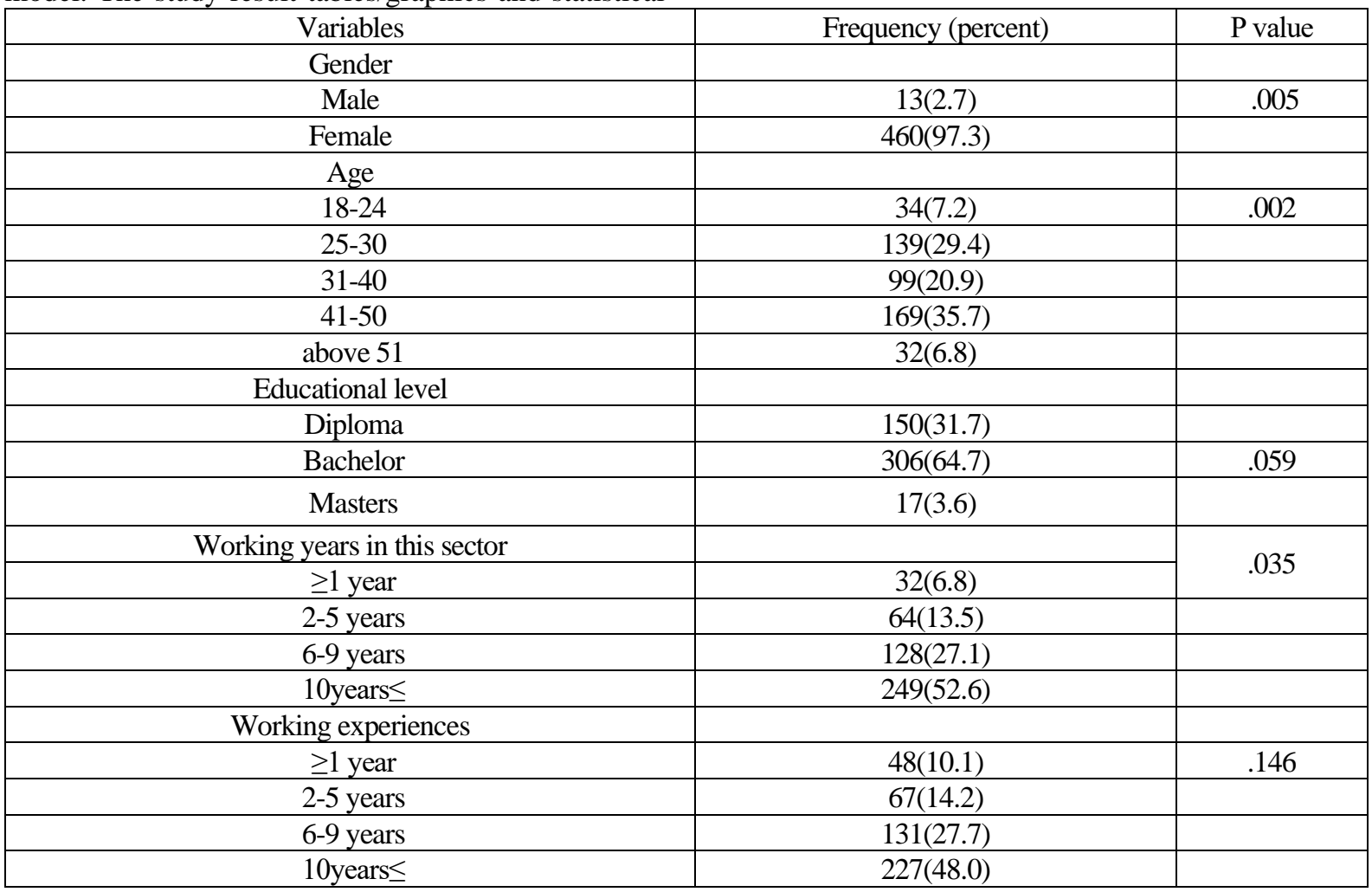

*NCID - National Center of Infectious Diseases

*NCC - National Center of Cancer

*NCMH - National Center of Mental Health

*NCTO - National Center of Traumatology and Orthopedics

Table 1 illustrates that the gender $-97.3 \%$ female and $2.7 \%$ male, but not the age and education statistical difference presents among the participants.

However, we can see statistical significance in the working area/place and the years of working there.

We identified the nurses' stress at three levels: high, medium/normal, and low. Table 2 reveals that the workplace low, normal and high stress level groups occupied $7.6 \%, 27.1 \%$ and $65.3 \%$, respectively. Moreover, they (cancer nurses) occupied the less percentage in the low and normal (19.7\%) stress groups. The NCTO nurses cover the least percentage in high stress levels $-53.7 \%$. data were developed and analyzed by Microsoft Excel2018 and Statistical Package for the Social Sciences (SPSS)-25.0. The standard deviation (SD) and regression data, differences between the groups were revealed by Student's test - the statistical difference should be at $p<0.05$. In addition, we measured the participants' saliva alpha amylase, arterial blood pressure, level of glucose in blood and heart pulse as the physiological indicators.

\section{Results}

A total of 473 nurses were included in the study, including $121 \mathrm{NCTO}, 89 \mathrm{NCMH}, 146 \mathrm{NCID}$, and 117 NCC. Meanwhile, 46 administrative workers, 75 doctors, 208 nurse-midwives, 105 cleaners, and 46 organizational workers participated in our study, too. The general information of the study participants is demonstrated in Table 1. 
Discussion: In 1978 Weiman and in 1990 Holmgren $^{1}$ had separately noted that workplace or work-related stress and stressors are the major reasons for such as sick-leave; physiological and psychological illnesses, work burnout and consequently these issues can cause the individual or organizational problems. We employed the Rice (1999) WPS self-esteemed questionnaire because we considered that our study participants will be categorized as relatively healthy, i.e. they never complain about being sick and leave the work. Furthermore, we decided that it would be reasonable if the participants assess themselves whether they are in work-related stress by reading and getting an idea what can be called workplace stress indeed $^{2}$.

It is clear that women dominate nursing around the world, however regardless of the work environment, requirements, or workload, regardless of gender all are exposed to workplace stress. The results of our study agree that it depends only on individuals. Our study gave proof that due to ANOVA the gender differences on workplace stress is absent $(\mathrm{F}=0.404),(\mathrm{p}=0,525)$ statistically. According to literature, workplace stress is often treated by the gender of nurses, but the results vary. Certain researchers noted that there is no gender difference in work stress 3 and others claimed that female nurses are more vulnerable to various occupational stresses than men4 moreover; some researchers figured out those female nurses are more intended for psychological stress; meanwhile the men tend to physiological stressors. 5 The results of this study are similar to the results of a 2013 study by Finnish researchers as well as Mauno that found that young nurses are less exposed to workplace stress than older nurses6. We agreed with the global studies that the nurses at younger age are less exposed to the work stress because they are working in a fellowship system and they are always relying on co-workers help. Particular researchers, such as Takase, Teraoka, and Yabase, suggested in a 2016 study that nurses over the age of twenty-five who want to keep their workplaces are more stressed than middle-aged and older nurses.7 The statistically significant differences in the stress levels $(F=1.923)$ and $(p=0.105)$. Above demonstrated results suggested that the onset of stress in a nurse's workplace depends on many different levels of social factors, such as age, gender, organizational characteristics, organization, place of work, and years of service. And these stressors have different impacts on individuals.

Conclusion: Nursing work-related stress levels were $\mathrm{F}=3.071, \mathrm{p}=0,028$; and it expressed statistical significant differences regarding the ANOVA analysis.

\section{STUDY OF THE POSSIBILITIES OF PREOPERATIVE CHEMOTHERAPY IN MULTIPLE METASTASIS OF COLORECTAL CANCER IN THE LIVER}

DOI: 10.31618/ESU.2413-9335.2020.1.77.958
Islamov Kh.D. ${ }^{\text {I } \text { Niyozova Sh.Kh. }{ }^{2}}$
${ }^{1}$ Republican Scientific and Practical Medical Center of Oncology
and Radiology of the Ministry of Health of the Republic of Uzbekistan
(RSSPMC OR MOH RUz),
${ }^{2}$ Tashkent medical academy

\section{SUMMARY}

Preoperative chemotherapy (CT) in 35 patients with colorectal cancer (CRC) with liver metastases demonstrated a high frequency of objective effects - in $22(62.9 \%)$ patients, stabilization was noted in $10(28.6 \%)$ cases. With bilobar liver metastases and the use of oxaliplatin-containing regimens, partial regression was $62.9 \%$. Side effects in most cases were clinically insignificant, no deaths were observed. The results obtained demonstrate the possibility of performing extended surgical operations in the majority of CRC patients with multiple liver metastases after preoperative CT.

Key words: colorectal cancer, liver metastases, preoperative chemotherapy

1

https://bmcpublichealth.biomedcentral.com/articles/10 .1186/s12889-019-7940-5/

${ }^{2}$ Rice, P. L. (1992). Stress \& Health (2nd ed.) Pacific Grove, California: Brooks/Cole Publishing Company. http://www2.uwstout.edu/content/lib/thesis/2000/2000braate nd.pdf - research paper

${ }^{3}$ Wong S., DeSantics G., Staudemayer N. The relationship between task interdependency and role stress: A revisit of the job demands-control model. J. Manage. Stud. 2007;44:284 303. doi: 10.1111/j.1467-6486.2007.00689.x. [CrossRef] [Google Scholar] [Ref list] 2. Proost K., de Witte H., de Witte K., Everts G. Burnout among nurses: Extending the job demand-control-support model with work-home interference. Psychologica Belgica. 2004;44:269-288. [Google Scholar] [Ref list])

${ }^{4}$ (1. Gunkel M., Lusk E., Wolf B., Li F. Gender specific effects at work: An empirical study of four countries. Gend.
Work Organ. 2007;14:56-79. doi: 10.1111/j.14680432.2007.00332.x. [CrossRef] [Google Scholar] [Ref list], 2. https://www.ncbi.nlm.nih.gov/pmc/articles/PMC3564148/,

${ }^{5}$ (Burke R. Work stress and women's health: Occupational status effect. J. Bus. Ethics. 2002;37:91-102. doi: 10.1023/A:1014734302972. [CrossRef] [Google Scholar] [Ref list])

${ }^{6}$ Mauno, S., Ruokolainen, M., \& Kinnunen U. (2013). Does aging make employees more resilient to job stress? Age as a moderator in the job stressor-well-being 127 relationship in three Finnish occupational samples. Aging \& mental health,17(4), 411-412. doi:10.1080/13607863.2012.747077

${ }^{7}$ Takase, M., Teraoka, S., \& Yabase, K. (2016). Retaining the nursing workforce: factorb contributing to the reduction of nurses' turnover intention in Japan. Journal of

Nursing Management, 24(1), 21-29. doi:10.1111/jonm.12266 